\title{
Advances in the management of insomnia
}

\author{
Wilfred R. Pigeon ${ }^{1,2,3 *}$, Todd M. Bishop ${ }^{2,5}$ and Jonathan A. Marcus ${ }^{4}$
}

\author{
Addresses: ${ }^{1}$ Center of Excellence for Suicide Prevention, Canandaigua VA Medical Center, 400 Fort Hill Avenue, Canandaigua, NY 14424, USA; \\ ${ }^{2}$ Center for Integrated Healthcare, 800 Irving Avenue, Syracuse, NY 13210, USA; ${ }^{3}$ Department of Psychiatry and; ${ }^{4}$ Department of Neurology, \\ University of Rochester Medical Center, Rochester, NY 14642, USA; ${ }^{5}$ Department of Psychology, 430 Huntington Hall, Syracuse University, \\ Syracuse \\ *Corresponding author: Wilfred R. Pigeon (Wilfred_Pigeon@URMC.Rochester.edu) \\ Fl000Prime Reports 2014, 6:48 (doi:10.12703/P6-48) \\ All Fl000Prime Reports articles are distributed under the terms of the Creative Commons Attribution-Non Commercial License \\ (http://creativecommons.org/licenses/by-nc/3.0/legalcode), which permits non-commercial use, distribution, and reproduction in any medium, \\ provided the original work is properly cited. \\ The electronic version of this article is the complete one and can be found at: http://f1000.com/prime/reports/m/6/48
}

\begin{abstract}
Insomnia is highly prevalent and associated with considerable morbidity. Several very efficacious treatments, both pharmacologic and non-pharmacologic, exist for the management of insomnia. New modes of delivery and new formulations of existing sedative-hypnotic medications have been introduced. Novel agents are still being developed and tested to arrive at a hypnotic that has limited side effects while still being efficacious. Innovations with respect to behavioral interventions, which are drastically under-utilized, have focused mainly on making these interventions more widely available through dissemination efforts, briefer formats and more accessible platforms.
\end{abstract}

\section{Introduction}

Insomnia presents a significant challenge to the health and wellness of individuals receiving treatment across a diverse array of settings. In a given year, approximately $10 \%$ of the world's population will report that they suffer from chronic or persistent insomnia [1-3]. These difficulties are even more prevalent in groups such as primary care patients [4], those with physical or mental health conditions [5], and the elderly [6]. In addition, insomnia is associated with worsened physical and emotional health, including higher risk for cardiovascular disease [7], depression [8], suicidal thoughts and behaviors [9], and diminished quality of life [10].

Individuals have attempted to manage insomnia with a variety of remedies including prescription medications, alcohol, herbal supplements, and over-the-counter sleep aids, with off-label medications being used almost as frequently as those approved for the treatment of insomnia [11]. In addition to these pharmacologic approaches, a number of non-pharmacologic approaches exist for the management of insomnia. Both types of approach have their place in the management of this sleep disorder; each has empirical support and each has shortcomings.

\section{"Older" sedative-hypnotic medications}

Barbiturates (e.g. butabarbital, secobarbital) were prescribed by physicians for much of the $20^{\text {th }}$ century, but their frequency of use slowed in favor of better tolerated benzodiazepines (e.g. flurazepam hydrochloride, quazepam, triazolam) and other medication classes. Benzodiazepines can produce significant short-term gains, such as decreased sleep onset latency and fewer nighttime awakenings [12]. However, these medications can also produce significant side effects including cognitive impairment, dizziness, morning sedation, and dependence [13].

Off label use of medications, without a US Food and Drug Administration (FDA) indication for the treatment of insomnia, is common [11]. Such agents are prescribed given their sedating side effects. They are typically prescribed for insomnia at lower doses than for their indicated uses. The most common of these are sedating antidepressants (e.g. trazodone, amitriptyline), and 
atypical antipsychotic medications (e.g. quetiapine, risperidone, olanzapine).

Similarly, over-the-counter sleep aids are based on the sedating side effect of antihistamines. The active ingredient is typically diphenhydramine or doxylamine, both first generation histamine $\mathrm{H}_{1}$ antagonists. Rapid tolerance to the sedative effects of diphenhydramine has been noted within four days of starting a $50 \mathrm{mg}$ dose of diphenhydramine [14]. For this reason, the routine use of diphenhydramine to treat chronic insomnia is not recommended.

\section{"Newer" sedative-hypnotic medications}

Following the introduction of zolpidem for insomnia in France in 1988 and its FDA approval in 1992, nonbenzodiazepine, benzodiazepine receptor agonists (BZRAs e.g. zolpidem, zaleplon, zopiclone, and eszopiclone) became the most commonly prescribed medication class for managing insomnia [15]. These newer BZRAs target the gamma aminobutyric acid (GABA) type A receptor complexes and have preferential affinity for the $\alpha-1$ subunit (or the $\alpha-3$ subunit in the case of eszopiclone) over the other receptor subunits $[16,17]$. It is not known whether this selective binding leads to fewer cognitive and psychomotor side effects than benzodiazepines, which do not have such binding specificity.

Each of these newer BZRAs has a slightly different half-life, affording clinicians the option of matching medication to individual insomnia presentation, such as sleep onset insomnia (trouble falling asleep) and sleep maintenance insomnia (trouble staying asleep). Zaleplon has the shortest half-life ( $\sim 1$ hour) making it useful for presentations of sleep onset insomnia. Zolpidem also has a short halflife in immediate release formulations (1.5 to 2.4 hours) useful for sleep onset insomnia, whereas an extended release formulation (2.8-2.9 hour half-life) is intended for both sleep onset and sleep maintenance insomnia. Eszopiclone, the single isomer of zopiclone, has a 6-9 hour half-life, making it appropriate for both onset and maintenance insomnia.

The popularity of the newer BZRAs is, in part, owing to their comparable efficacy to benzodiazepines, combined with shorter half-lives and their potentially more limited side effect profile. As recently reviewed [18], common adverse effects include headache, dizziness, nausea, somnolence, fatigue, and, with respect to eszopiclone, an unpleasant or metallic taste. Although some longterm trials (e.g. 12 months) have not found evidence of tolerance, dependence or rebound insomnia [19], these remain concerns with long-term use of the newer BZRAs [18]. A meta-analysis concluded that, although indirect comparisons suggest that newer BZRAs were safer than older medications, all hypnotic classes evaluated pose a risk of harm [20]. These authors also note that safety data in vulnerable populations like the elderly are lacking. Finally, there is concern about the association of hypnotic use with considerable morbidity and mortality [21-26].

Ramelteon is the last of the "newer" sleep medications, receiving FDA approval in 2005. It does not act upon the GABA system, but is a melatonin receptor agonist that selectively binds to $\mathrm{MT}_{1}$ and $\mathrm{MT}_{2}$ receptors. Similar to exogenous administration of melatonin, it has phase shifting effects on endogenous circadian rhythms [27]. It is generally well-tolerated with more effects on sleep onset, but not sleep maintenance problems [28] and, unlike the BZRAs, is not categorized as a controlled substance [29].

\section{Neutraceuticals and supplements}

Despite some early indications of the promise of several foods, herbs or supplements in treating insomnia, there are generally few high-quality clinical trials to support their use. Existing clinical trial data, reviews and/or meta-analyses of chamomile [30], tart cherries [31], L-tryptophan $[32,33]$, and valerian $[34,35]$ suggest very mixed support, at best, for their impact on insomnia. There is more consistent support, and well-designed trials, for the use of exogenous melatonin for insomnia, although the effect sizes achieved with melatonin are small [36].

\section{Non-pharmacologic approaches to insomnia management}

Non-pharmacologic approaches to the management of insomnia have been available for some time and have varying degrees of empirical support as reported extensively in practice parameters [37], consensus statements [38], evidence reviews [39], and several meta-analyses [40-42]. The following brief summaries reflect the agreements across these resources. Sleep hygiene education [43], which generally consists of simple recommendations to improve sleep (e.g. exercise daily, avoid caffeine in the evening), is frequently used due to its brevity and ease of delivery, but has very limited empiric support as a stand-alone treatment [44]. Cognitive therapy [45] (e.g. identifying and challenging cognitions that interfere with sleep) has been identified as having potential utility in the management of insomnia, though additional evidence is needed for its full endorsement as a stand-alone treatment. Relaxation training [46] alone has been shown to improve several features of insomnia. Sleep restriction therapy [47], which limits the patient's time in bed to the amount of time they report sleeping, 
serves to strengthen the homeostatic drive for sleep and consolidate sleep in a limited window of sleep opportunity. Based on daily self-report of total sleep time and the efficiency of using the prescribed sleep period (averaged over one week periods), the prescribed sleep window is increased in small increments. This approach has strong empirical support, though surprisingly few trials have investigated sleep restriction as a single therapy. Stimulus control therapy [48], which does not prescribe times in bed, nonetheless asks patients to limit time in bed by going to bed only when sleepy and leaving bed if unable to sleep after 15-20 minutes. It also includes instructions to remove sleep-interfering stimuli (including behaviors like watching television in bed) from the bedroom environment. It is considered the most efficacious non-pharmacologic treatment for insomnia.

Overall, with the exception of sleep hygiene, these interventions can be expected to have some efficacy when delivered as stand-alone insomnia treatments. The most efficacious non-pharmacologic insomnia treatment, however, is a multi-component intervention referred to as cognitive behavioral therapy for insomnia (CBT-I), which typically combines sleep psychoeducation, stimulus control, sleep restriction therapy, sleep hygiene, cognitive therapy and relaxation training [40-42,49]. It is customary to list increased daytime sleepiness as a potential side-effect of sleep restriction therapy, but there are no published data in this regard.

Are existing insomnia treatments good enough? Although there are numerous evidence-based interventions available to manage insomnia, a number of shortcomings of these approaches have been identified. For instance, the efficacy of benzodiazepines, newer BZRAs and sedating antidepressants is well-established, but safety concerns remain for each of these medication classes [20].

As recently as 2013, due to the risk for morning impairment, the FDA recommended that the bedtime dose of zolpidem be lowered [50]. This follows earlier warnings for zolpidem regarding case reports of behaviors such as driving, nocturnal eating, making phone calls, or having sex while not fully awake $[2,51]$. And, notwithstanding some longer term trials of up to 12 months of nightly administration [18,52], concerns about long term use remain [20]. In addition, pharmacologic intervention can often occur while neglecting the behavioral and cognitive factors that contribute to insomnia. Historically, a major shortcoming of CBT-I has been the limited availability of clinicians trained in this approach [53]. In addition, the standard duration of CBT-I, whether delivered individually or in group formats, is 6-8 sessions. Although, this can be considered brief, time-limited therapy, it still requires fairly significant patient involvement and may not be feasible to deliver in some settings, such as primary care clinics. Due to these shortcomings, modifications to existing approaches and completely novel approaches to insomnia management continue to be developed and tested.

\section{Advances in pharmacotherapy for insomnia}

One approach to advancing insomnia care has been to develop different formulations of and/or delivery systems for BZRAs. These have included oral and nasal sprays, sublingual tablets, and inhalation systems, but whether these have advanced treatment remains to be shown [54]. A similar approach was taken with respect to introducing a low-dose formulation of doxepin, an older, tricyclic antidepressant with hypnotic effects. Here, the strategy was to reduce dosages from the typical 50-200 mg range to 3 and $6 \mathrm{mg}$ tablets in order to, putatively, benefit from selective antagonism for $\mathrm{H}_{1}$ receptors without activity at other receptors. Two placebo-controlled trials have now demonstrated that low dose doxepin improves both sleep maintenance and early morning awakenings, with no withdrawal effects upon discontinuation $[55,56]$.

The alternative approach is to develop novel hypnotic medications, especially those that do not target the GABAergic system. In this regard, two classes of medication in particular that have reached phase III clinical trials appear to hold some promise. These include agents specifically targeting the $5-\mathrm{HT}_{2 \mathrm{~A}}$ serotonin receptor subtype (e.g. volinanserin, eplivanserin, pruvanserin) and agents targeting the orexin (also called the hypocretin) system (e.g. almorexant, suvorexant). With respect to $5-\mathrm{HT}_{2 \mathrm{~A}}$ inverse agonists, compounds that have been developed have minimal affinity to dopamine, histamine and adrenergic receptors, compared to existing sedating antidepressants such as mirtazapine and risperidone. Theoretically this may lead to fewer potential side effects. Generally, these newer agents have been associated with improvement in sleep maintenance and increases in slow wave sleep [57]. Nonetheless, despite positive phase III efficacy data, eplivanserin development was discontinued in 2009. The development of esmirtazapine (the single isomer version of mirtazipine), volinanserin, and pruvanserin were also suspended. Little is known about the reasons that prompted these decisions.

The orexin system has been implicated in sleep-wake regulation [58] and particularly the maintenance of arousal [59], with important putative links to insomnia $[1,60]$. There is considerable interest in orexin receptor antagonism for the treatment of insomnia [61] as an alternative to increasing sedation, and therefore decreasing arousal. 
Almorexant, a dual orexin receptor antagonist that blocks both $\mathrm{OX}_{1}$ and $\mathrm{OX}_{2}$ receptors [62-64], was the first such compound to reach phase III studies, but the almorexant program was discontinued in 2011, due to concerns about unspecified adverse effects [65]. A separate dual orexin receptor antagonist, suvorexant, has had promising results in its clinical trials $[66,67]$. Despite some suggestions of limited side effects on cognition [68], the maximum therapeutic dose of suvorexant $(40 \mathrm{mg}$ ) was shown to produce cognitive and psychomotor impairment. The field now awaits whether FDA approval will be granted for a lower dose that may have a therapeutic effect without lasting morning effects. Meanwhile, a companion compound to suvorexant, MK-6096, awaits further testing [69]. Notably, all human polysomnography data from these orexin antagonists suggest that they increase rapid eye movement (REM) sleep [70], in a dose-dependent manner [71], raising concerns about symptoms related to narcolepsy, given the presence of REM abnormalities in patients with narcolepsy and the role of orexin in narcolepsy [61].

\section{Advances in behavioral treatments for insomnia} There are very limited side effects associated with nonpharmacologic interventions for insomnia. The only exception may be the short term increase in daytime sleepiness that arises with sleep restriction therapy in the initial weeks of treatment. Instead, the long standing shortcoming in delivering CBT-I, for instance, has been a shortage of clinicians [72]. Two recent developments are making a dent in this problem. One has been a large-scale dissemination effort by the US Veterans Administration to train clinicians to deliver CBT-I [73] with preliminary evidence of the effectiveness of these clinicians now available [74]. The second advance has been to make CBT-I programs accessible via the internet. Here again, findings (including randomized trials) suggest that this mode of delivery is efficacious and rivals effect sizes attained in face-to-face delivery of CBT-I [75-79].

A related approach to increasing the uptake of behavioral insomnia interventions has been to develop briefer versions of these successful interventions. This includes the introduction of a "primary-care friendly cognitive behavioral insomnia therapy" which consists of only two sessions [80] and a "Brief Behavioral Treatment for Insomnia" that involves an initial 45 minute session focused on education, stimulus control, and sleep restriction followed by a booster session two weeks later [81]. Here again, both approaches have demonstrated efficacy on standard insomnia outcomes.

A unique approach to a "brief" intervention is a one session intervention called intensive sleep retraining [82], although that one session lasts approximately 25 hours. This treatment involves acute sleep deprivation, followed by repeated opportunities to initiate sleep presented every half hour, putatively leading to counter-conditioning of learned insomnia as the patient generates multiple successful attempts at initiating sleep. In a randomized trial, patients in the intervention arm achieved significantly greater improvements in sleep onset latency, total sleep time, and sleep efficiency and these gains were maintained for 6 months [82].

Finally, although evidence supports the two pure behavioral components of CBT-I (stimulus control therapy and sleep restriction therapy), no dismantling studies of these treatments had been conducted until recently. In just such a study $(n=179)$ of individuals with primary insomnia, stimulus control therapy alone, sleep restriction therapy alone and combined stimulus control and sleep restriction were compared to waitlist control [83]. All conditions were associated with significant improvements relative to the control condition. The strongest effects and highest remission rates, however, were observed in the combined condition.

\section{Other recent changes relevant to the management of insomnia}

Historically, a gradual shift away from considering insomnia to be "just a symptom" towards recognizing it as a disorder occurred during the 1990 s and early $21^{\text {st }}$ century. The 2005 NIH consensus statement on chronic insomnia [13] hastened a shift away from the term "secondary insomnia" in favor of "comorbid insomnia" to describe insomnia that co-occurs with other conditions. The consensus document recognized that insomnia most frequently presents with other conditions. Most recently, due to the questionable relevance in clinical practice of even this distinction, the $5^{\text {th }}$ edition Diagnostic and Statistical Manual of Mental Disorders (DSM-5) [84] replaced the diagnosis of "primary insomnia" with "insomnia disorder" to specifically avoid differentiation between primary and comorbid insomnia. A similar change was made in insomnia classification in the recently published International Classification of Sleep Disorders - Third Edition (ICSD-3) [85].

These changes follow considerable (and ongoing) work documenting that insomnia presenting with one or more of a variety of conditions, from depression and posttraumatic stress disorder to chronic pain and cancer, can be managed with current insomnia treatments, either alone or in combination with interventions for the cooccurring condition(s) (e.g. [86-92]). This work also shows that sleep improvements associated with the 
insomnia intervention tend to generalize to modest improvements in the co-occurring condition(s).

\section{Summary and next steps}

Numerous efficacious interventions exist for the management of insomnia, yet the disorder remains undertreated. Pharmacologic options that are efficacious, safe and do not pose the risk of tolerance are still needed. At this point, suvorexant is the only truly "new" hypnotic likely to reach market in the next year. The development of newer agents will no doubt continue, despite setbacks in this regard. Advances in the nonpharmacologic interventions will likely continue to be in terms of addressing barriers to engagement through clinician training, brief but effective adaptations of existing approaches, and novel delivery methods. One approach that has only recently been proposed is the suggestion that insomnia treatment be delivered in a stepped care model $[93,94]$, such that graduated levels of behavioral interventions would be provided (e.g. self-help approaches, brief interventions, standard CBTI with a specialist). We are likely to see evaluations of this approach in the next few years. Finally, surprisingly little work has been done to test the clinical guideline that pharmacotherapy and behavioral interventions be combined [95]. One trial has demonstrated the efficacy of this approach [96], but a definitive trial that tests the efficacy of short term hypnotic use (e.g. 1-3 weeks) during the early phase of behavioral treatment would be informative.

\section{Abbreviations}

BZRA, benzodiazepine receptor agonist; CBT-I, cognitive behavioral therapy for insomnia; FDA, US Food and Drug Administration; GABA, gamma aminobutyric acid; REM, rapid eye movement.

\section{Disclosures}

Wilfred R. Pigeon was previously on the Purdue Pharma, LLP Speakers bureau for Intermezzo and receives royalties from Ivy Press, Inc. for Sleep Manual: Training your Mind and Body to Achieve the Perfect Night's Sleep. The authors declare that they have no other disclosures or competing interests to report.

\section{Acknowledgments}

This material is, in part, the result of work supported with resources and the use of facilities at the Center of Excellence for Suicide Prevention, VA Medical Center, Canandaigua, NY and the Center for Integrated Healthcare, VA Medical Center, Syracuse, NY. The contents do not represent the views of the Department of Veterans Affairs or the United States Government.

\section{References}

I. Ohayon MM: Epidemiology of insomnia: what we know and what we still need to learn. Sleep Med Rev 2002, 6:97-I I I.

2. Walsh JK, Coulouvrat C, Hajak G, Lakoma MD, Petukhova M, Roth T, Sampson NA, Shahly V, Shillington A, Stephenson J], Kessler RC: Nighttime insomnia symptoms and perceived health in the America Insomnia Survey (AIS). Sleep 201 I, 34:997-101 I.

\section{FIOOOPrime}

3. Morin CM, LeBlanc M, Daley M, Gregoire JP, Mérette C: Epidemiology of insomnia: prevalence, self-help treatments, consultations, and determinants of help-seeking behaviors. Sleep Med 2006, 7:123-30.

\section{FlOOOPrime} RECOMMENDED

4. Shochat T, Umphress J, Israel AG, Ancoli-Israel S: Insomnia in primary care patients. Sleep 1999, 22(Suppl 2):S359-65.

5. Sivertsen B, Krokstad S, Øverland S, Mykletun A: The epidemiology of insomnia: associations with physical and mental health. The HUNT-2 study. J Psychosom Res 2009, 67:109-16.

6. Ancoli-Israel S: Sleep and aging: prevalence of disturbed sleep and treatment considerations in older adults. J Clin Psychiatry 2005, 66(Suppl 9):24-30 quiz; 42-3.

7. Vgontzas AN, Liao D, Bixler EO, Chrousos GP, Vela-Bueno A: Insomnia with objective short sleep duration is associated with a high risk for hypertension. Sleep 2009, 32:491-7.

\section{FIOOOPrime
RECOMMENDED}

8. Baglioni C, Battagliese G, Feige B, Spiegelhalder K, Nissen C, Voderholzer U, Lombardo C, Riemann D: Insomnia as a predictor of depression: a meta-analytic evaluation of longitudinal epidemiological studies. J Affect Disord 2011, 135:10-9.

\section{FlOOOPrime} RECOMMENDED

9. Pigeon WR, Pinquart M, Conner K: Meta-analysis of sleep disturbance and suicidal thoughts and behaviors. J Clin Psychiatry 2012, 73:el 160-7.

FlOOOPrime

RECOMMENDED

10. Léger D, Morin CM, Uchiyama M, Hakimi Z, Cure S, Walsh JK: Chronic insomnia, quality-of-life, and utility scores: comparison with good sleepers in a cross-sectional international survey. Sleep Med 2012, I3:43-5I.

II. Pigeon WR, Bishop TM, Marcus JA: Current pharmacological and nonpharmacological options for the management of insomnia. Clin Med Insights: Therapeutics 2013, 5:I5I-162.

12. Holbrook AM, Crowther R, Lotter A, Cheng C, King D: Metaanalysis of benzodiazepine use in the treatment of insomnia. CMAJ 2000, 162:225-33.

13. National Institutes of Health State of the Science Conference statement on Manifestations and Management of Chronic Insomnia in Adults, June I3-I 5 2005. Sleep 2005, 28: 1049-57.

14. Richardson GS, Roehrs TA, Rosenthal L, Koshorek G, Roth T: Tolerance to daytime sedative effects of $\mathrm{HI}$ antihistamines. J Clin Psychopharmacol 2002, 22:5 I I-5.

15. Walsk JK, Roth T: Pharmacologic Treatment of Insomnia. In: Principles and Practice of Sleep Medicine. $5^{\text {th }}$ ed. Edited by Kryger $\mathrm{MH}$, Roth T, Dement WC. Philadelphia: Saunders; 20II, 905-I5.

16. Beer B, leni JR, Wu WH, Clody D, Amorusi P, Rose J, Mant T, Gaudreault J, Cato A, Stern W: A placebo-controlled evaluation of single, escalating doses of CL 284,846, a non-benzodiazepine hypnotic. J Clin Pharmacol 1994, 34:335-44.

17. Jia $F$, Goldstein PA, Harrison NL: The modulation of synaptic GABA(A) receptors in the thalamus by eszopiclone and zolpidem. J Pharmacol Exp Ther 2009, 328:1000-6. 
18. Neubauer DN: Novel developments in the pharmacological management of insomnia. J of Lifelong Learning in Psychiatr 2014, 7:38-44.

19. Roth T, Walsh JK, Krystal A, Wessel T, Roehrs TA: An evaluation of the efficacy and safety of eszopiclone over 12 months in patients with chronic primary insomnia. Sleep Med 2005, 6:487-95.

20. Buscemi N, Vandermeer B, Friesen C, Bialy L, Tubman M, Ospina M, Klassen TP, Witmans M: The efficacy and safety of drug treatments for chronic insomnia in adults: a meta-analysis of RCTs. J Gen Intern Med 2007, 22:1335-50.

\section{FIOOOPrime \\ RECOMMENDED}

21. Belleville G: Mortality hazard associated with anxiolytic and hypnotic drug use in the National Population Health Survey. Can J Psychiatry 2010, 55:558-67.

22. Carlsten A, Waern M: Are sedatives and hypnotics associated with increased suicide risk of suicide in the elderly? BMC Geriatr 2009, 9:20.

23. Kripke DF: Greater incidence of depression with hypnotic use than with placebo. BMC Psychiatry 2007, 7:42.

24. Kripke DF: Who should sponsor sleep disorders pharmaceutical trials? J Clin Sleep Med 2007, 3:67I-3.

25. Kripke DF, Langer RD, Kline LE: Hypnotics' association with mortality or cancer: a matched cohort study. BMJ Open 20I2, 2:e000850.

26. Rod NH, Vahtera J, Westerlund H, Kivimaki M, Zins M, Goldberg M, Lange $T$ : Sleep disturbances and cause-specific mortality: Results from the GAZEL cohort study. Am J Epidemiol 201I, 173:300-9.

27. Richardson GS, Zee PC, Wang-Weigand S, Rodriguez L, Peng X: Circadian phase-shifting effects of repeated ramelteon administration in healthy adults. J Clin Sleep Med 2008, 4:456-6I.

\section{FlOOOPrime \\ RECOMMENDED}

28. Roth T, Seiden D, Sainati S, Wang-Weigand S, Zhang J, Zee P: Effects of ramelteon on patient-reported sleep latency in older adults with chronic insomnia. Sleep Med 2006, 7:312-8.

\section{FlOOOPrime
RECOMMENDED}

29. Food and Drug Administration: Rozerem ${ }^{\circledR}$ (ramelteon) tablets. [March 14, 2007: Takeda] MedWatch drug labeling changes. Rockville, MD; April 2007.

30. Zick SM, Wright BD, Sen A, Arnedt JT: Preliminary examination of the efficacy and safety of a standardized chamomile extract for chronic primary insomnia: a randomized placebocontrolled pilot study. BMC Complement Altern Med 20II, I I:78.

31. Pigeon WR, Carr M, Gorman C, Perlis ML: Effects of a tart cherry juice beverage on the sleep of older adults with insomnia: a pilot study. J Med Food 2010, 13:579-83.

32. Hudson C, Hudson SP, Hecht T, MacKenzie J: Protein source tryptophan versus pharmaceutical grade tryptophan as an efficacious treatment for chronic insomnia. Nutr Neurosci 2005, 8:121-7.

33. Sarris J, Byrne GJ: A systematic review of insomnia and complementary medicine. Sleep Med Rev 201 I, 15:99-106.

34. Taibi DM, Landis CA, Petry H, Vitiello MV: A systematic review of valerian as a sleep aid: safe but not effective. Sleep Med Rev 2007, II:209-30.

35. Salter S, Brownie S: Treating primary insomnia - the efficacy of valerian and hops. Aust Fam Physician 2010, 39:433-7.

36. Buscemi N, Vandermeer B, Hooton N, Pandya R, Tjosvold L, Hartling L, Baker G, Klassen TP, Vohra S: The efficacy and safety of exogenous melatonin for primary sleep disorders. A metaanalysis. J Gen Intern Med 2005, 20:I I5I-8.
37. Morgenthaler T, Kramer M, Alessi C, Friedman L, Boehlecke B Brown T, Coleman J, Kapur V, Lee-Chiong T, Owens J, Pancer J, Swick T: Practice parameters for the psychological and behavioral treatment of insomnia: an update. An american academy of sleep medicine report. Sleep 2006, 29:1415-9.

38. NIH State-of-the-Science Conference Statement on manifestations and management of chronic insomnia in adults. NIH Consens State Sci Statements 2005, 22: I-30.

39. Morin CM, Bootzin RR, Buysse DJ, Edinger JD, Espie CA, Lichstein KL: Psychological and behavioral treatment of insomnia:update of the recent evidence (1998-2004). Sleep 2006, 29:1398-4I4.

40. Irwin MR, Cole JC, Nicassio PM: Comparative meta-analysis of behavioral interventions for insomnia and their efficacy in middle-aged adults and in older adults 55+ years of age. Health Psychol 2006, 25:3-14.

4I. Morin CM, Culbert JP, Schwartz SM: Nonpharmacological interventions for insomnia: a meta-analysis of treatment efficacy. Am J Psychiatry 1994, I5 I: I I72-80.

42. Murtagh DR, Greenwood KM: Identifying effective psychological treatments for insomnia: a meta-analysis. J Consult Clin Psychol 1995, 63:79-89.

43. Hauri P: Current Concepts: The Sleep Disorders. The Upjohn Company Kalamazoo, Michigan, 1977.

44. Stepanski EJ, Wyatt JK: Use of sleep hygiene in the treatment of insomnia. Sleep Med Rev 2003, 7:215-25.

45. Morin CM: Cognitive-behavioral approaches to the treatment of insomnia. J Clin Psychiatry 2004, 65(Suppl I6):33-40.

\section{FlOOOPrime
RECOMMENDED}

46. Lichstein KL: Clinical Relaxation Strategies. New York: Wiley; 1988.

47. Spielman AJ, Saskin P, Thorpy MJ: Treatment of chronic insomnia by restriction of time in bed. Sleep 1987, 10:45-56.

\section{FlOOOPrime} RECOMMENDED

48. Bootzin RR, Nicassio P: Behavioral treatments for insomnia. In M Hersen, RH Eisler \& PM Miller (Eds.), Progress in Behavior Modification, I-47. New York, NY: Academic Press, 1978.

49. Okajima I, Komada Y, Inoue Y: A meta-analysis on the treatment effectiveness of cognitive behavioral therapy for primary insomnia. Sleep and Biological Rhythms 201 I, 9:24-34

50. FDA Drug Safety Communication: Risk of next-morning impairment after use of insomnia drugs; FDA requires lower recommended doses for certain drugs containing zolpidem. (Ambien, Ambien, CR, Edluar, and Zolpimist).

5I. Greene D. Dear healthcare professional letter regarding important updated prescribing information for Ambien $®$ (zolpidem tartrate) tablets and Ambien $C R \circledast$ (zolpidem tartrate) extended-release tablets. Bridgewater, NJ: Sanofi-Aventis US; 2007 Mar.

52. Roehrs TA, Randall S, Harris E, Maan R, Roth T: Twelve months of nightly zolpidem does not lead to rebound insomnia or withdrawal symptoms: a prospective placebo-controlled study. J Psychopharmacol (Oxford) 2012, 26: 1088-95.

\section{FlOOOPrime
RECOMMENDED}

53. Pigeon WR, Crabtree VM, Scherer MR: The future of behavioral sleep medicine. J Clin Sleep Med 2007, 3:73-9.

54. Neubauer DN: ZolpiMist ${ }^{\mathrm{TM}}$ : a new formulation of zolpidem tartrate for the short-term treatment of insomnia in the US. Nat Sci Sleep 2010, 2:79-84.

55. Roth T, Rogowski R, Hull S, Schwartz H, Koshorek G, Corser B, Seiden D, Lankford A: Efficacy and safety of doxepin I $\mathbf{~ m g}, \mathbf{3} \mathbf{~ m g}$, and $6 \mathrm{mg}$ in adults with primary insomnia. Sleep 2007, 30:1555-61.

\section{FlOOOPrime}

\section{RECOMMENDED}

56. Krystal $A D$, Lankford $A$, Durrence $H H$, Ludington $E$, Jochelson $P$, Rogowski R, Roth T: Efficacy and safety of doxepin 3 and $\mathbf{6} \mathbf{~ m g}$ in 
a 35-day sleep laboratory trial in adults with chronic primary insomnia. Sleep 201 I, 34:1433-42.

\section{FlOOOPrime}

57. Teegarden BR, AI Shamma H, Xiong $Y$ : 5-HT(2A) inverse-agonists for the treatment of insomnia. Curr Top Med Chem 2008, 8:969-76.

\section{FlOOOPrime}

\section{RECOMMENDED}

58. Saper CB, Chou TC, Scammell TE: The sleep switch: hypothalamic control of sleep and wakefulness. Trends Neurosci 200I, 24:726-3I.

59. Sakurai T, Mieda M: Connectomics of orexin-producing neurons: interface of systems of emotion, energy homeostasis and arousal. Trends Pharmacol Sci 201 I, 32:45 I-62.

60. Saper CB, Cano G, Scammell TE: Homeostatic, circadian, and emotional regulation of sleep. J Comp Neurol 2005, 493:92-8.

61. Brisbare-Roch C, Dingemanse J, Koberstein R, Hoever P, Aissaoui H, Flores S, Mueller C, Nayler O, van Gerven J, de Haas Sanne L, Hess P, Qiu C, Buchmann S, Scherz M, Weller T, Fischli W, Clozel M, Jenck F: Promotion of sleep by targeting the orexin system in rats, dogs and humans. Nat Med 2007, I 3:150-5.

62. Hoever P, Haas S de, Winkler J, Schoemaker RC, Chiossi E, van Gerven J, Dingemanse J: Orexin receptor antagonism, a new sleep-promoting paradigm: an ascending single-dose study with almorexant. Clin Pharmacol Ther 2010, 87:593-600.

63. Hoever P, Dorffner G, Beneš $H$, Penzel T, Danker-Hopfe $H$, Barbanoj MJ, Pillar G, Saletu B, Polo O, Kunz D, Zeitlhofer J, Berg S, Partinen M, Bassetti CL, Högl B, Ebrahim IO, HolsboerTrachsler E, Bengtsson H, Peker Y, Hemmeter U, Chiossi E, Hajak G, Dingemanse J: Orexin receptor antagonism, a new sleepenabling paradigm: a proof-of-concept clinical trial. Clin Pharmacol Ther 2012, $91: 975-85$.

64. Hoever P, de Haas Sanne L, Dorffner G, Chiossi E, van Gerven, Joop $M$, Dingemanse J: Orexin receptor antagonism: an ascending multiple-dose study with almorexant. J Psychopharmacol (Oxford) 2012, 26:1071-80.

65. Actelion: Actelion and GSK discontinue clinical development of almorexant. [http://wwwl.actelion.com/en/our-company/newsand-events/index.page?newsld=|483|35]

66. Herring WJ, Snyder E, Budd K, Hutzelmann J, Snavely D, Liu K, Lines C, Roth T, Michelson D: Orexin receptor antagonism for treatment of insomnia: a randomized clinical trial of suvorexant. Neurology 2012, 79:2265-74.

\section{FlOOOPrime RECOMMENDED}

67. Sun H, Kennedy WP, Wilbraham D, Lewis N, Calder N, Li X, Ma J, Yee KL, Ermlich S, Mangin E, Lines C, Rosen L, Chodakewitz J, Murphy GM: Effects of suvorexant, an orexin receptor antagonist, on sleep parameters as measured by polysomnography in healthy men. Sleep 2013, 36:259-67.

\section{FlOOOPrime}

\section{RECOMMENDED}

68. Uslaner JM, Tye SJ, Eddins DM, Wang X, Fox SV, Savitz AT, Binns J, Cannon CE, Garson SL, Yao L, Hodgson R, Stevens J, Bowlby MR, Tannenbaum PL, Brunner J, Mcdonald TP, Gotter AL, Kuduk SD, Coleman PJ, Winrow CJ, Renger J]: Orexin receptor antagonists differ from standard sleep drugs by promoting sleep at doses that do not disrupt cognition. Sci Transl Med 20।3, 5:I79ra44.

\section{FlOOPPrime \\ RECOMMENDED}

69. Winrow CJ, Gotter AL, Cox CD, Tannenbaum PL, Garson SL, Doran SM, Breslin MJ, Schreier JD, Fox SV, Harrell CM, Stevens J, Reiss DR, Cui D, Coleman PJ, Renger JJ: Pharmacological characterization of MK-6096 - a dual orexin receptor antagonist for insomnia. Neuropharmacology 2012, 62:978-87.
70. Hoyer D, Jacobson LH: Orexin in sleep, addiction and more: is the perfect insomnia drug at hand? Neuropeptides 2013, 47:477-88.

7I. Herring WJ, Snyder E, Budd K, Hutzelmann J, Snavely D, Liu K, Lines C, Roth T, Michelson D. Orexin receptor antagonism for treatment of insomnia: a randomized clinical trial of suvorexant. Neurology 2012, 79:2265-2274.

72. Lamberg L: Despite effectiveness, behavioral therapy for chronic insomnia still underused. JAMA 2008, 300:2474-5.

73. Manber R, Carney C, Edinger J, Epstein D, Friedman L, Haynes PL, Karlin BE, Pigeon W, Siebern AT, Trockel M: Dissemination of CBTI to the non-sleep specialist: protocol development and training issues. J Clin Sleep Med 2012, 8:209-I8.

74. Karlin BE, Trockel M, Taylor CB, Gimeno J, Manber R: National dissemination of cognitive behavioral therapy for insomnia in veterans: therapist- and patient-level outcomes. J Consult Clin Psychol 2013, 81:912-7.

\section{FlOOOPrime}

\section{RECOMMENDED}

75. Espie CA, Kyle SD, Williams C, Ong JC, Douglas NJ, Hames P, Brown, June SL: A randomized, placebo-controlled trial of online cognitive behavioral therapy for chronic insomnia disorder delivered via an automated media-rich web application. Sleep 2012, 35:769-8I.

\section{FlOOOPrime}

\section{RECOMMENDED}

76. Ström L, Pettersson R, Andersson G: Internet-based treatment for insomnia: a controlled evaluation. J Consult Clin Psychol 2004, 72: I I3-20.

77. Ritterband LM, Thorndike FP, Gonder-Frederick LA, Magee JC, Bailey ET, Saylor DK, Morin CM: Efficacy of an Internet-based behavioral intervention for adults with insomnia. Arch Gen Psychiatry 2009, 66:692-8.

78. van Straten A, Cuijpers P: Self-help therapy for insomnia: a meta-analysis. Sleep Med Rev 2009, I3:6I-7I.

\section{FlOOOPrime
RECOMMENDED}

79. Vincent N, Lewycky S: Logging on for better sleep: RCT of the effectiveness of online treatment for insomnia. Sleep 2009, 32:807-I5.

\section{FlOOOPrime
RECOMMENDED}

80. Edinger JD, Sampson WS: A primary care "friendly" cognitive behavioral insomnia therapy. Sleep 2003, 26: I77-82.

\section{FlOOOPrime}

\section{RECOMMENDED}

8I. Germain A, Moul DE, Franzen PL, Miewald JM, Reynolds CF, Monk TH, Buysse DJ: Effects of a brief behavioral treatment for late-life insomnia: preliminary findings. J Clin Sleep Med 2006, 2:403-6.

\section{FIOOOPrime
RECOMMENDED}

82. Harris J, Lack L, Kemp $K$, Wright $H$, Bootzin R: A randomized controlled trial of intensive sleep retraining (ISR): a brief conditioning treatment for chronic insomnia. Sleep 2012, 35:49-60.

\section{FIOOOPrime}

83. Epstein DR, Sidani S, Bootzin RR, Belyea MJ: Dismantling multicomponent behavioral treatment for insomnia in older adults: a randomized controlled trial. Sleep 20I2, 35:797-805.

84. American Psychiatric Association. Diagnostic and statistical manual of mental disorders (5th ed.). Arlington, VA: American Psychiatric Publishing, 2013.

85. American Academy of Sleep Medicine. International classification of sleep disorders - Third Edition. Darien, IL: American Academy of Sleep Medicine; 2014. 
86. Edinger JD, Olsen MK, Stechuchak KM, Means MK, Lineberger MD, Kirby A, Carney CE: Cognitive behavioral therapy for patients with primary insomnia or insomnia associated predominantly with mixed psychiatric disorders: a randomized clinical trial. Sleep 2009, 32:499-5I0.

87. Fava M, McCall WV, Krystal A, Wessel T, Rubens R, Caron J, Amato D, Roth T: Eszopiclone co-administered with fluoxetine in patients with insomnia coexisting with major depressive disorder. Biol Psychiatry 2006, 59:1052-60.

88. Fleming L, Randell K, Harvey C, Espie CA: Does cognitive behaviour therapy for insomnia reduce clinical levels of fatigue, anxiety and depression in cancer patients? Psychooncology 2014.

89. Manber R, Bernert RA, Suh S, Nowakowski S, Siebern AT, Ong JC: CBT for insomnia in patients with high and low depressive symptom severity: adherence and clinical outcomes. J Clin Sleep Med 20II, 7:645-52.

90. Manber R, Edinger JD, Gress JL, San Pedro-Salcedo Melanie, G Kuo, TF Kalista: Cognitive behavioral therapy for insomnia enhances depression outcome in patients with comorbid major depressive disorder and insomnia. Sleep 2008, 31 : 489-95.
9I. Pigeon WR, Moynihan J, Matteson-Rusby S, Jungquist CR, Xia Y, Tu X, Perlis ML: Comparative effectiveness of CBT interventions for co-morbid chronic pain \& insomnia: a pilot study. Behav Res Ther 20I2, 50:685-9.

92. Ulmer $\mathrm{C}$, Bosworth $\mathrm{H}$, Edinger J, et al.: $\mathbf{A}$ brief intervention for sleep disturbance in ptsd. J Gen Intern Med 2010, 25:206-13.

93. Espie CA: "Stepped care": a health technology solution for delivering cognitive behavioral therapy as a first line insomnia treatment. Sleep 2009, 32:1549-58.

94. Mack LJ, Rybarczyk BD: Behavioral treatment of insomnia: a proposal for a stepped-care approach to promote public health. Nat Sci Sleep 20I I, 3:87-99.

95. Schutte-Rodin S, Broch L, Buysse D, Dorsey C, Sateia M: Clinical guideline for the evaluation and management of chronic insomnia in adults. J Clin Sleep Med 2008, 4:487-504.

96. Morin $\mathrm{CM}$, Vallières $\mathrm{A}$, Guay $\mathrm{B}$, Ivers $\mathrm{H}$, Savard J, Mérette $\mathrm{C}$, Bastien C, Baillargeon L: Cognitive behavioral therapy, singly and combined with medication, for persistent insomnia: a randomized controlled trial. JAMA 2009, 30I:2005-I5.

\section{FloOOPrime}

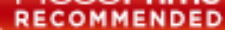

